\title{
EXPERIMENTAL INVESTIGATIONS ON CORROSION MODEL OF WELDED 6061 ALUMINUM EXPOSED IN NaCI SOLUTION
}

\author{
Y.P. Asmara ${ }^{*}$, J.P. Siregar ${ }^{1}$, L.H. Shah ${ }^{1}$ and C. Tezara ${ }^{2}$ \\ ${ }^{1}$ Faculty of Mechanical Engineering, Universiti Malaysia Pahang \\ 26600 Pekan, Pahang, Malaysia \\ *Email: ${ }^{1}$ YPanca@ hotmail.com \\ Phone: +6094246239; Fax: +609424622 \\ ${ }^{2}$ Department of Mechanical Engineering, \\ Faculty of Science, Technology, Engineering and Mathematics, \\ INTI International University \\ 71800 Nilai, Negeri Sembilan, Malaysia
}

\begin{abstract}
Interpreting both each segmented region and multi-reactions for self-corrosion is important when investigating the corrosion rate in a welded structure. This research studied weld corrosion occurring on aluminum 6061 that can be considered from the electrical circuit concept. The research studied the corrosion process on two types of filler which were 4043 and 4047 filler. The electrical circuit model and corrosion test revealed that the heat affected zone (HAZ) region behaved as an anode and showed a higher corrosion rate for both types of filler. Samples using filler 4043 had a higher corrosion rate than filler 4047. Under an optical microscope, filler 4043 was seen to display inhomogeneous microstructures which relate to the corrosion process. Using the electrical model, study of the galvanic effects on each part of the weld regions showed realistic correlations to simulate the corrosion process in welded samples.
\end{abstract}

Keywords: Preferential weld corrosion; corrosion simulation; mixed potential theories; heat affected zone; galvanic corrosion.

\section{INTRODUCTION}

Weld aluminum corrosion has grown to be a major concern for automotive industries. Many researchers have investigated weld corrosion, especially in order to predict the corrosion rate [1-4]. As reported in open literature [5], galvanic corrosion attacks welded metal and becomes a destructive source for automotive bodies and metal infrastructures. Understanding the corrosion process mechanism on welded structures will help to control the corrosion rate and protect the metal structures. The most common problem with welded aluminum is galvanic corrosion, notably where the material is exposed to a marine environment [6]. This type of corrosion occurs due to the dissimilar microstructures of the weld material (WM), heat affected zone (HAZ) and base metal (BM). Thermal cycling during welding creates dissimilar microstructural heterogeneities which cause galvanic effects and are considered to be the main sources of weld corrosion [5,6]. Galvanic corrosion has been found at locations in different regions of the material due to differences in microstructure. One region on the welded metal can act as either an anode or cathode, depending on the electro-negativity of the metal. If the WM and HAZ are anodic to the BM, galvanic current will start from these 
anodic areas [5] and [6]. Furthermore, corrosion can also occur on the metal due to the electro-chemical process between the metal and electrolyte (self-corrosion) [7].

Aluminum is considered to be corrosion-resistant which is attributed to the thin surface layer of aluminum oxide that forms due to the metal's exposure to the air. This oxide layer can protect the aluminum from further oxidation. Aluminum starts to corrode when the metal is galvanically in contact with other metal $[8,9]$. The corrosion resistance of aluminum can be also reduced by aqueous salts, particularly in the presence of dissimilar metals. Aluminum is oxidized by water to produce hydrogen following this reaction.

$$
2 \mathrm{Al}+3 \mathrm{H}_{2} \mathrm{O} \rightarrow \mathrm{Al}_{2} \mathrm{O}_{3}+3 \mathrm{H}_{2}
$$

Models to calculate corrosion consist of many different approaches. Each model predicts the corrosion rate in a different manner. All of these were developed from different systems and assumptions. During the last decade, the models were developed by using only limited variables, whereas new variables are now indicated as making contributions in corrosion models [10]. The following provides several methods commonly used to calculate the multiple corrosion process. First is mixed potential theory, which is used in electrochemistry and relates the potentials and currents from different corrosion reactions. It is an electrode potential resulting from the simultaneous reaction of a single redox couple [11]. According to the mixed-potential, any electrochemical reaction can be divided into oxidation and reduction reactions. Under this theory, the total current is zero and the corroding metal is charged neutral. Second is a mechanistic model to calculate uniform corrosion using fundamental physicochemical laws. These cover electrochemical reactions and the diffusion process $[12,13]$. In the case of corrosion occurring on the metal surface, this can be expressed mathematically by using mechanistics data. These corrosion mechanisms are based on several assumptions which can be described as follows: convective diffusion, molecular diffusion and diffusion via solid film [14]. In this work, the corrosion process on two types of filler, 4043 and 4047 weld filler, will be studied using an electrical circuit model. This model will be used to predict the corrosion behavior of weld samples focusing on the heat affcted zone (HAZ), weld materials (WM) and base materials $(\mathrm{BM})$. Samples were immersed in $3 \% \mathrm{NaCl}$ as representative of seawater. Under immersed conditions, the samples were tested to measure the corrosion rate and corrosion potentials. Data from experiments were used to fit the electrical circuit models to simulate the corrosion process in real conditions.

\section{EXPERIMENTAL SETUP}

\section{Samples}

The materials used were aluminum 6061 with a thickness of $2 \mathrm{~mm}$. The material plates were cut into $100 \mathrm{~mm}$ length and $50 \mathrm{~mm}$ width using a MVS-C 6/31 shearing machine. The filler metals used were $4043 \mathrm{AlSi}$ and $4047 \mathrm{AlSi}$. The chemical composition of the base material and filler metals is displayed in Tables 1 and 2 . 
Table 1. Material composition.

\begin{tabular}{llllllllll}
\hline Elements & $\mathrm{Cu}$ & $\mathrm{Si}$ & $\mathrm{Mn}$ & $\mathrm{Mg}$ & $\mathrm{Cr}$ & $\mathrm{C}$ & $\mathrm{P}$ & $\mathrm{S}$ & $\mathrm{Fe}$ \\
\hline Al 6061 & 0.205 & 0.680 & 0.0829 & 0.884 & 0.167 & - & - & - & 0.404 \\
Steel & 0.0083 & $<0.0050$ & 0.286 & - & 0.0843 & 0.0683 & 0.0281 & 0.0290 & 98.6 \\
\hline
\end{tabular}

Table 2. Fillers composition.

\begin{tabular}{lllllllll}
\hline Elements & $\mathrm{Si}$ & $\mathrm{Fe}$ & $\mathrm{Cu}$ & $\mathrm{Zn}$ & $\mathrm{Mn}$ & $\mathrm{Mg}$ & $\mathrm{Ti}$ & $\mathrm{Al}$ \\
\hline 4043 & $4.5-6.0$ & $<0.80$ & $<0.30$ & $<0.10$ & $<0.05$ & $<0.05$ & $<0.20$ & $\mathrm{Bal}$ \\
4047 & $11.0-13.0$ & $<0.80$ & $<0.30$ & $<0.20$ & $<0.05$ & $<0.10$ & - & $\mathrm{Bal}$ \\
\hline
\end{tabular}

\section{Sample Preparation}

The materials were cut based on different microstructure regions (Figure 1(a)), which include the weld material (WM), heat affected zone (HAZ) and base metal (BM). Each weld region was machined into a surface area of $1 \mathrm{~cm}^{2}$. All of the weld regions were soldered with insulated copper wire for electrical connection and cold mounted as shown in Figure 1(b).

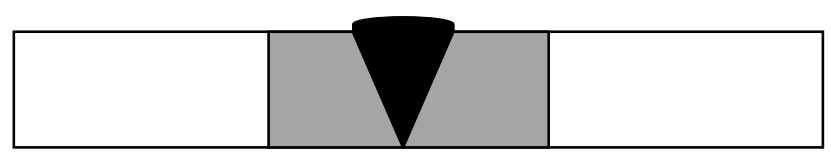

BM

HAZ WM

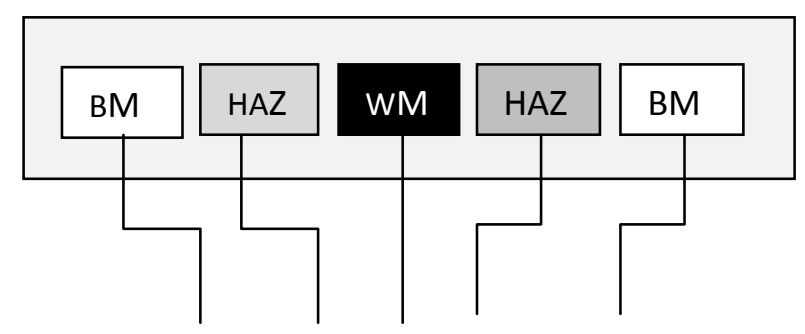

(b)

Figure 1. (a) Segment of weld regions and (b) samples held on the block of epoxy.

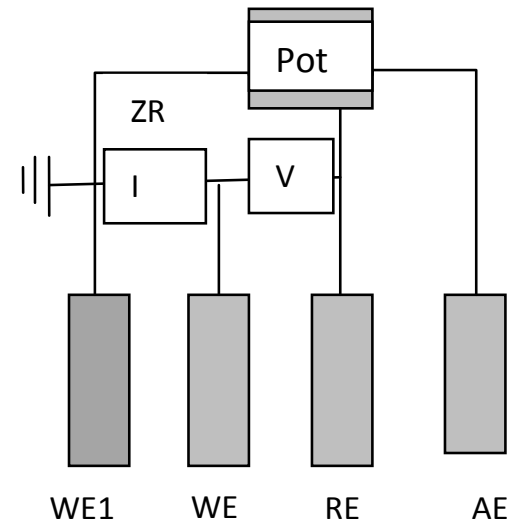

(a)

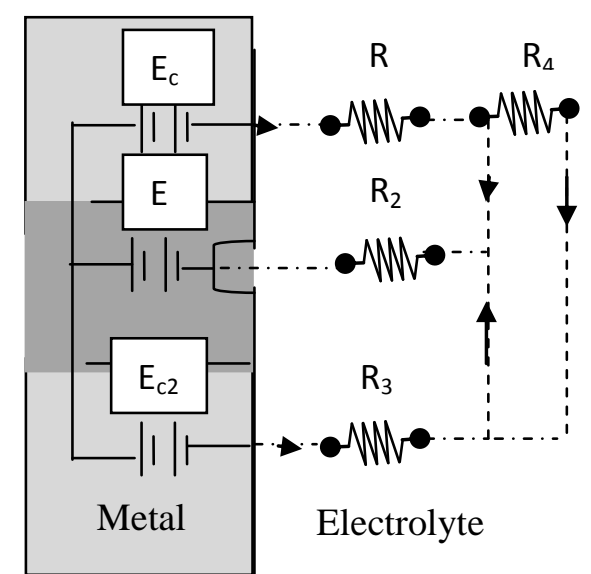

(b)

Figure 2. (a) Schematic potentiostatic/dynamic tests to measure corrosion rate,

(b) equivalent circuit for cell experiment circuit used to represent the cell solution. 


\section{Electrochemical Corrosion Test}

The self-corrosion rate and galvanic corrosion rate of the samples were measured using the linear polarisation resistance (LPR) technique. The experiments were conducted using solutions containing $3 \% \mathrm{NaCl}$. The LPR corrosion rate for all weld regions was calculated using the Stern-Geary coefficient, B of $25 \mathrm{mV}$. All the experiments to test the corrosion rate were set at a temperature of $25^{\circ} \mathrm{C}$. The procedure is similar to ASTM Experimental test G 5-94 [15]. Further interpretation can be generated using the assumption that the equivalent electrical circuit consists of an arrangement of resistors. Through this circuit, the properties of the surface can be identified as a circuit analog. The model's equivalent circuits are presented in Figure 2.

\section{RESULTS AND DISCUSSION}

A summary of comparison data analysis taken from the experiment, the equivalent circuit and the mixed potential theories model for the two types of weld filler are presented in this section. The sole potentials on the BM, the WZ and the HAZ are shown in Table 3. It can be seen that in the potentiostatic test, the most anodic region was located in the HAZ region for both the 4043 and 4047 weld filler, with a current density of $10^{-6} \mathrm{~A} / \mathrm{cm}^{2}$. The HAZ showed a higher corrosion rate, followed by BM and $\mathrm{WM}$, respectively.

Table 3. Data used to calculate corrosion rate for self-corrosion calculations.

\begin{tabular}{lllll}
\hline & \multicolumn{2}{l}{ Potentiostatic } & \multicolumn{2}{l}{ Potentiodynamic } \\
\cline { 2 - 5 } & 4043 & 4047 & 4043 & 4047 \\
\hline Ecorr $(\mathrm{BM})(\mathrm{mV})$ & -0.76 & -0.68 & -1100 & -900 \\
Ecorr $(\mathrm{HAZ})(\mathrm{mV})$ & -0.80 & -0.79 & -900 & -947 \\
Ecorr $(\mathrm{WM})(\mathrm{mV})$ & -0.75 & -0.67 & -700 & -671 \\
$\mathrm{R} 1(\mathrm{BM})\left(\mathrm{K} \Omega \mathrm{cm}^{-2}\right)$ & - & - & 157.73 & 250 \\
$\mathrm{R} 2(\mathrm{HAZ})\left(\mathrm{K} \Omega \mathrm{cm}^{-2}\right)$ & - & - & 31.47 & 49.88 \\
$\mathrm{R} 3(\mathrm{WM})\left(\mathrm{K} \Omega \mathrm{cm}^{-2}\right)$ & - & - & 1252.96 & 627.97 \\
$\log$ Icorr $\left(\mathrm{A} / \mathrm{cm}^{2}\right)$ & - & - & -6.8 & -7.0 \\
Log Icorr $\left(\mathrm{A} / \mathrm{cm}^{2}\right)$ & - & - & -6.1 & -6.3 \\
Log Icorr $\left(\mathrm{A} / \mathrm{cm}^{2}\right)$ & - & - & -7.7 & -7.4 \\
Total corr. current $\left(\mathrm{A} / \mathrm{cm}^{2}\right)$ & & & -6.0 & -6.2 \\
\hline
\end{tabular}

Table 4. Data used to calculate corrosion rate for galvanic corrosion calculations.

\begin{tabular}{lllll}
\hline & Model & \multicolumn{3}{l}{ Galv. Exp. } \\
\cline { 2 - 5 } & 4043 & 4047 & 4043 & 4047 \\
\hline Ecorr (BM-HAZ) $(\mathrm{mV})$ & -1000 & -900 & -800 & -700 \\
Ecorr (HAZ-WM) $(\mathrm{mV})$ & -900 & -810 & -790 & -760 \\
Ecorr $(\mathrm{WM}-\mathrm{BM})(\mathrm{mV})$ & -790 & -790 & -890 & -1100 \\
R1 $(\mathrm{BM}-\mathrm{HAZ})\left(\mathrm{K} \Omega \mathrm{cm}^{-2}\right)$ & 125.29 & 157.73 & 3.14 & 3.14 \\
R2(HAZ-WM) $\left(\mathrm{K} \Omega \mathrm{cm}^{-2}\right)$ & 498.81 & 62.79 & 0.995 & 3.96 \\
R3(WM-BM) $\left(\mathrm{K} \Omega \mathrm{cm}^{-2}\right)$ & 62.79 & 99.52 & 396.22 & 6.27 \\
Log Icorr(A/cm & -5.0 & -4.9 & -5.1 & -5.1 \\
Log Icorr(A/cm & -4.7 & -4.9 & -4.6 & -5.2 \\
LogIcorr(A/cm $)$ & -4.7 & -4.8 & -7.2 & -5.4 \\
Total corr. current $\left(\mathrm{A} / \mathrm{cm}^{2}\right)$ & $-5,5$ & -6.1 & -4.5 & -4.7 \\
\hline
\end{tabular}


Table 4 shows the data on the galvanic corrosion, considering the coupled effects between the two segmented regions. Table 4 shows that galvanic corrosion was initiated from the region between the BM and HAZ with a current density of $10^{-5} \mathrm{~A} / \mathrm{cm}^{2}$ for both types of filler. The data show that the highest corrosion rate is found at the region between the HAZ and WM. As seen in the table, the HAZ-WM samples have a higher corrosion rate (4043 filler) than the BM-HAZ or BM-WM samples.

Table 5 presents the galvanic corrosion in real conditions where all the regions (WM-HAZ-BM) were coupled in the electrolyte. Data recorded from Table 5 was used to verify the analog circuit to construct the corrosion kinetics that represent the real preferential weld corrosion, as presented in Figure 3. The recorded data in Table 5 reveals that filler 4043 yielded a higher corrosion rate. This different corrosion rate may relate to the chemical composition, as filler 4043 has silicon ( $\mathrm{Si}$ ) content. Although this filler has lower $\mathrm{Zn}$ and $\mathrm{Mg}$ contents, the effects of $\mathrm{Si}$ show a dominant factor in the reducing corrosion rate. The results were also similar to experiments conducted by [16, 17]. In order to obtain a more realistic model to determine the corrosion current, the galvanic regions were simulated in an analog circuit by varying the weld resistivity parameters in the electric circuit, as seen in Figure 3. The simulation will be fitted as accurately as possible to the real corrosion obtained from the experimental data in Table 5.

Table 5. Corrosion rate data comparison calculated using models.

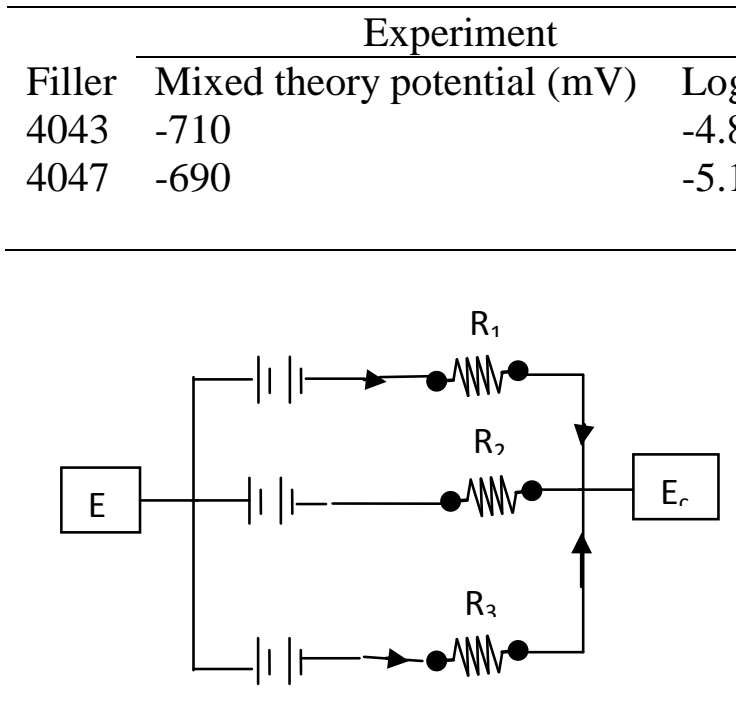

(a)

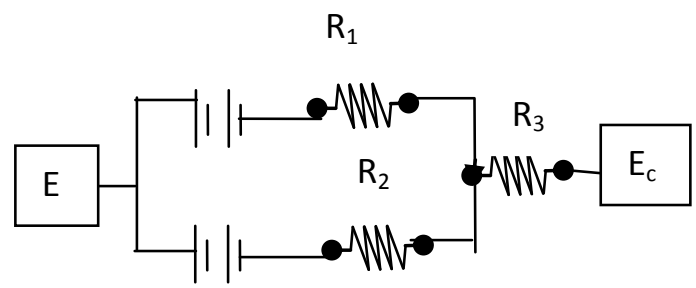

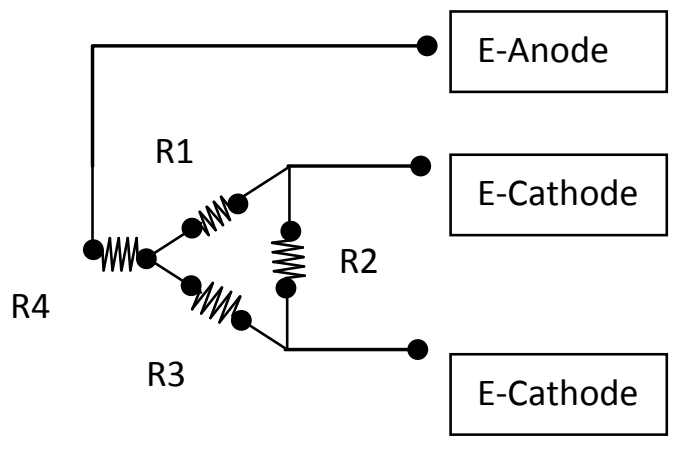

(b)

(c)

Figure 3. Several analog corrosion circuits representing preferential weld corrosion. 
The data from Table 5 show several values of polarisation resistance, current density and corrosion potential that match the analog circuit from Figure 4. Applying analog circuit calculation, the preferential mechanism of weld corrosion was observed as shown in the circuit in Figure 3(c) for 4043 weld filler and in Figure 3(a) for 4047 weld filler. Weld samples using filler 4043 show combination reactions between the parallel and series analog circuit, while filler 4047 behaved in a parallel manner during the corrosion process. The corrosion reactions on filler 4043 show that the most reactive area is in the HAZ. This process tends to produce pitting corrosion where the anodes are continously reactive. By contrast with filler 4047, the most reactive area (anodes) was located on the weld metal and HAZ, thus the corrosion process starts from these two regions. The rate of corrosion in the anode will determine the forms of corrosion, as found by $[15,18,19]$.

\section{Corrosion Mechanism Proposed}

From the analog circuit as presented in Figure 3, it is decided to obtain the best agreement with the data from Table 5, which measures the corrosion rate in real conditions. As seen in Figure 4, the samples welded with filler 4043 had one anode (HAZ) and two cathodes (BM and WM), while the samples welded with filler 4047 had two anodes that corroded simultaneously. This corrosion conditions model can be used to predict the types of corrosion produced. The weld using 4043 filler tends to result in pitting corrosion, while filler 4047 will cause uniform corrosion.

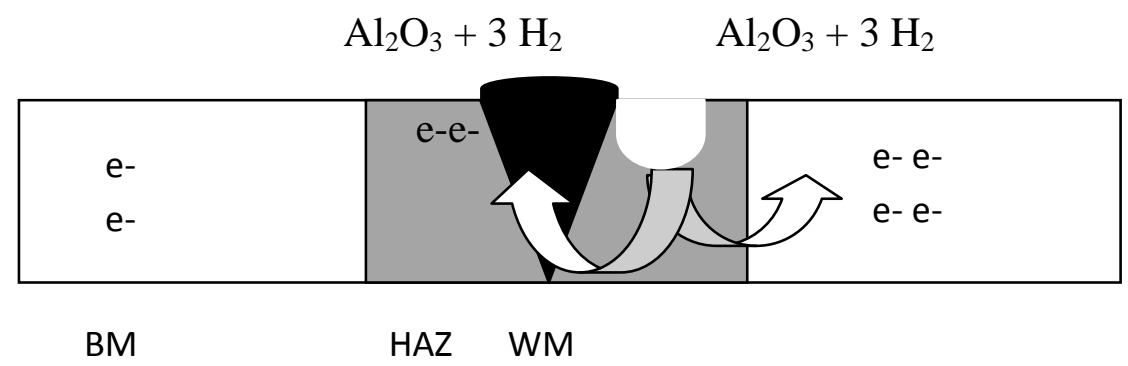

(a)

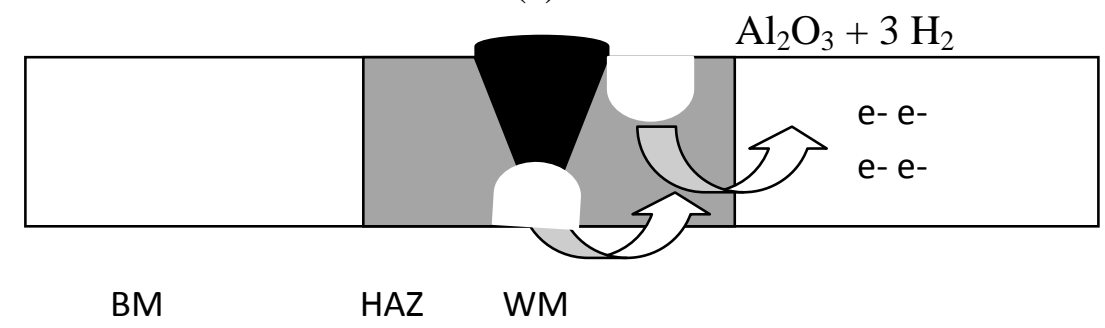

Figure 4. Model corrosion prosess on (a) filler 4043; and (b) filler 4047.

\section{Microstructure}

Figure 5 exhibits the cross-sections and the type of microstructure formed on the specimens. When welding with a filler metal (or joining two different materials), the fusion zone composition was different from the base metal composition and the weld metal crystal is dissimilar to the base metal crystal structures. The differential microstructure is believed to govern the corrosion rate [20,21]. 

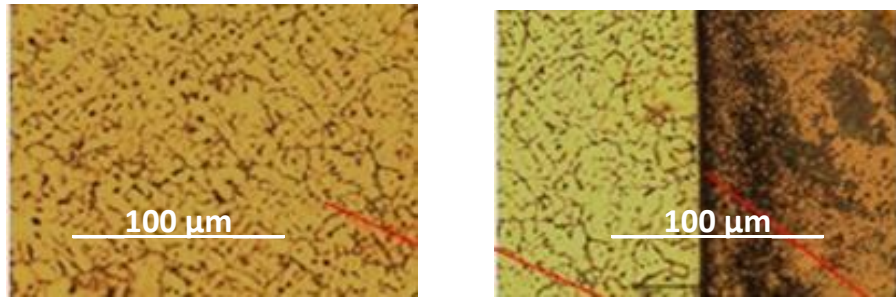

Heterogeneous nuclei (BM) Dendrite (HAZ-WM)

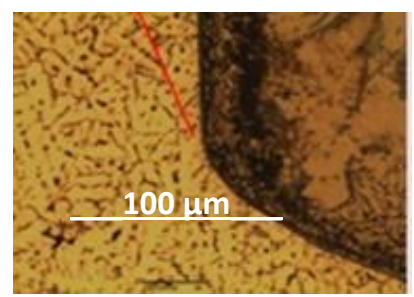

Cellular dendrite (HAZ-WM)

Figure 5. Cross-section and microstructure of the specimen.

\section{CONCLUSIONS}

Polarization and galvanic electrochemical studies can be used to predict the corrosion mechanism on welded samples. During this work a new and more objective method for the model corrosion process is demonstrated by modifying the corrosion parameters. The HAZ region behaves as anode and shows a higher corrosion rate. The sample with filler 4043 had a higher corrosion rate than the 4047 filler. The electrical circuit model can also be used to predict galvanic effects on each part of the weld regions to simulate both individual corrosion processes and combinations of galvanic corrosion. The differential microstructures on the HAZ, WM, and BM regions affect the corrosion rate and govern the types of corrosion.

\section{ACKNOWLEDGEMENTS}

The author would like to thank the supervisor and technical staffs in Universiti Malaysia Pahang in fasilitating financial support under project no. RDU130337.

\section{REFERENCES}

[1] Nešić S. Key issues related to modelling of internal corrosion of oil and gas pipelines-A review. Corrosion Science. 2007;49:4308-38.

[2] Jackson TS, Martin PE, Posey R. Surface response design to study the effect of low oxygen levels on carbon dioxide corrosion environments. NACE International. 2009; 1-23.

[3] Abd Razak NA, Ng SS. Investigation of Effects of MIG Welding on Corrosion Behaviour of AISI 1010 Carbon Steel. Journal of Mechanical Engineering and Sciences. 2014;7:1168-78.

[4] Haque MM, Limon SA, Moniruzzaman M, Bepari MMA. Corrosion comparison of galvanized steel and aluminum in aqueous environments. International Journal of Automotive and Mechanical Engineering. 2014;9:1758-67.

[5] Shah L, Akhtar Z, Ishak M. Investigation of aluminum-stainless steel dissimilar weld quality using different filler metals. International Journal of Automotive and Mechanical Engineering. 2013;8:1121-31.

[6] Ridha M, Fonna S, Huzni S, Supardi J, Ariffin A. Atmospheric corrosion of structural steels exposed in the 2004 tsunami-affected areas of Aceh. 
International Journal of Automotive and Mechanical Engineering. 2013;7:101422.

[7] Alawadhi K, Robinson M. Preferential weld corrosion of X65 pipeline steel in flowing brines containing carbon dioxide. Corrosion Engineering, Science and Technology. 2011;46:318-29.

[8] Kimura M, Sakata K, Shimamoto K. Corrosion resistance of martensitic stainless steel OCTG in severe corrosion environments. Corrosion 2007. 2007.

[9] Sathari NAA, Shah LH, Razali AR. Investigation of single-pass double-pass techniques on friction stir welding of aluminium. Journal of Mechanical Engineering and Sciences. 2014;7:1053-61.

[10] Marchebois H, Piette M, Ladeuille L, Rouviere DS, Bosch C, Pleschiutschnig J, et al. Development Of A C125 High Strength Low Alloy Steel For Octg: Ssc Mapping In Slightly Sour Environment. Corrosion: NACE International; 2008.

[11] Sun W. Kinetics of iron carbonate and iron sulfide scale formation in $\mathrm{CO}_{2} / \mathrm{H}_{2} \mathrm{~S}$ corrosion: Ohio University; 2006.

[12] Aberle D, Agarwal D. High performance corrosion resistant stainless steels and nickel alloys for oil \& gas applications. Corrosion. 2008. http://www.parrinst .com/wp-content/uploads/downloads/2011/07/Parr_Inconel-Incoloy-MonelNickel-Corrosion-Info.pdf

[13] Asmara YP, Siregar JP, Cionita T, Alias J. Electrochemical Behaviour of High Stress Steel (AISI 4340) in $\mathrm{CO}_{2}$ Environments with the Presence of $\mathrm{H}_{2}$ Gas. Applied Mechanics \& Materials. 2014; 695: 98-101.

[14] Kopliku A, Tabinor M, Ryder J, Dent P. High strength modified martensitic stainless steel production tubing for sour wells. Corrosion: NACE International. 2009; 1-14.

[15] Standard A. Standard reference test method for making potentiostatic and potentiodynamic anodic polarization measurements. Designation G5, Annual Book of ASTM Standards. 1990;1-3.

[16] Faget L. The Effect of Silicon on the Electrochemical Corrosion Resistance of Carbon Steel: California Polytechnic State University, San Luis Obispo; 2014.

[17] Asmara YP, Ismail MC. Study Combinations Effects of $\mathrm{HAc}$ in $\mathrm{H}_{2} \mathrm{~S} / \mathrm{CO}_{2}$ Corrosion. Journal of Applied Sciences.11:1821-6.

[18] Gulbrandsen E. Acetic acid and carbon dioxide corrosion of carbon steel covered with iron carbonate. Corrosion: NACE International. 2007; 1-22.

[19] Charde N. Microstructure and fatigue properties of dissimilar spot welded joints of AISI 304 and AISI 1008. International Journal of Automotive and Mechanical Engineering. 2013;7:882-899.

[20] Chehuan T, Dreilich V, de Assis KS, de Sousa FV, Mattos OR. Influence of multipass pulsed gas metal arc welding on corrosion behaviour of a duplex stainless steel. Corrosion Science. 2014;86:268-74.

[21] Asmara YP, Ismail MC. Efficient design of response surface experiment for corrosion prediction in $\mathrm{CO}_{2}$ environments. Corrosion Engineering, Science and Technology.47:10-8. 